\title{
O SISTEMA ELKONIN-DAVIDOV: UM BOSQUEJO DA TEORIA DO ENSINO DESENVOLVIMENTAL
}

\section{ARTIGO ORIGINAL}

CAMILO, Marcos Gomes ${ }^{1}$

CAMILO, Marcos Gomes. O sistema Elkonin-Davidov: um bosquejo da teoria do ensino desenvolvimental. Revista Científica Multidisciplinar Núcleo do Conhecimento. Ano 06, Ed. 06, Vol. 06, pp. 142-158. Junho de 2021. ISSN: 24480959, Link de acesso: https://www.nucleodoconhecimento.com.br/educacao/ensinodesenvolvimental, DOI: 10.32749/nucleodoconhecimento.com.br/educacao/ensinodesenvolvimental

\section{RESUMO}

Neste artigo apresenta-se a essência da pesquisa de Elkonin e Davidov sobre a didática desenvolvimental a partir dos pressupostos desenvolvidos por Vigotski, a respeito do papel da educação e do ensino, na construção do psiquismo humano. Destaca-se, nesse ínterim, o entendimento da importância da conexão entre educação e desenvolvimento, a definição do papel da escola na transformação da realidade dos seus alunos, a finalidade da construção do pensamento teórico científico no aluno e, ainda, como os conceitos científicos, que são mediados, podem instituir na tomada da consciência. Acerca especificamente do sistema Elkonin-Davidov, enfatizou-se o desenvolvimento do pensamento que foi e é considerado uma revolução pedagógica. E, por fim, expõe as principais contribuições teóricas e práticas que o sistema efetivou, através de pesquisas em laboratório, escolas experimentais e na rede pública de educação básica.

\footnotetext{
${ }^{1}$ Mestrando do Programa de Pós-Graduação em Educação da Faculdade de Inhumas - FACMAIS.
}

RC: 88296

Disponível em: https://www.nucleodoconhecimento.com.br/educacao/ensino-desenvolvimental 
Palavras-chave: Ensino desenvolvimental, Teoria histórico-cultural, Ensino/aprendizagem.

\section{INTRODUÇÃO}

O contexto vivenciado, no que diz respeito ao processo de ensino/aprendizagem, tem sido um grande desafio aos educadores nessa geração. Educar com responsabilidade, mediar o processo de ensinagem, não é uma tarefa fácil e requer dedicação, conhecimento, formação adequada, formação continuada, conhecimento teóricos científicos. Ser professor é uma profissão de natureza social, pois preza a mudança, a transformação de seus alunos no que é relativo à aprendizagem.

A teoria histórico-cultural de Vygotsky colabora com muitos professores sobre o como lidar com o aluno a fim de transformá-lo enquanto ser social. É uma teoria que defende que a transformação acontece já nos primeiros anos de existência, em que a criança se apropria dos saberes e os reproduz em suas diferentes atividades ao longo de sua vida, formando assim seus hábitos, sua personalidade, suas ideias, sua intelectualidade.

A teoria de Vygotsky, histórico-cultural, também conhecida como Escola de Vygotsky, foi desenvolvida no século XX na União Soviética e tinha como tese que o ser humano é um ser de natureza especialmente social. Era preciso identificar, aos olhos da psicologia, como o ser humano desenvolve sua inteligência e sua consciência, tornando-o diferente dos animais, base para a construção da didática desenvolvimental.

O sistema Elkonin-Davidov, elaborado com base nos pressupostos de Vygotsky tem justamente enfoque no ensino do desenvolvimento do pensamento. Foi um método experimental que propunha a investigação das potencialidades dos sujeitos, crianças ou não, em idade escolar. Os autores se engajaram na transformação tanto social, quanto pessoal dos alunos.

RC: 88296

Disponível em: https://www.nucleodoconhecimento.com.br/educacao/ensino-desenvolvimental 
A presença do professor nesse processo de desenvolvimento é indispensável, pois ele conduzirá o aluno a dominar suas estratégias de pensamento, para então leva-lo a adquirirem seus conhecimentos. Um conceito muito importante é o da tarefa, uma vez que esta deve ser elaborada de forma a promover o desenvolvimento, conforme as intencionalidades com objetivo comum ou necessidades do aluno. Assim o aluno desenvolverá suas potencialidades, sua autonomia intelectual, pois terá internalizado os conhecimentos teóricos necessários para exercício da cidadania.

Dessa forma, o presente texto busca trazer uma investigação bibliográfica, na busca por responder à questão-chave: quais as principais contribuições do sistema ElkoninDavidov para o âmbito educacional? Para tal, irá então tratar, em seu primeiro capítulo, dos princípios que deram origem ao ensino desenvolvimental; o segundo capítulo trará uma explanação sobre do se trata o sistema Elkonin-Davidov e, por fim, o terceiro capítulo trará as contribuições do trabalho de Elkonin e Davidov para a implementação de metodologias de investigação científica.

\section{PRINCÍPIOS DO ENSINO DESENVOLVIMENTAL}

Tratemos inicialmente, deste grande pesquisador em psicologia pedagógica, que faz parte da terceira geração da escola científica e que desenvolveu seu trabalho no pósguerra, a partir de 1950. Seu nome é Vasily Vasilyevich Davidov, um russo que baseou toda sua pesquisa nos postulados de Lev Semenovitch Vygotsky e em sua teoria histórico-cultural.

Davidov objetivou suas pesquisas no desenvolvimento do pensamento de crianças e também dos jovens, por considerar que a escola era insuficiente para suas formações. Seu ensejo era que a escola, enquanto sistema de ensino, orientasse seus alunos de modo que os levassem a serem sujeitos autônomos, fomentando assim o desenvolvimento mental.

RC: 88296

Disponível em: https://www.nucleodoconhecimento.com.br/educacao/ensino-desenvolvimental 
Sua teoria, acerca do ensino/aprendizagem destaca muito bem como a educação influencia o desenvolvimento de seus alunos, ajudando-os a desenvolverem-se criticamente, com pensamentos abstratos e dialéticos.

Em sua pesquisa no campo da psicologia pedagógica, Davidov destacou a importante conexão entre a educação e o desenvolvimento. Assim, por meio do convívio com adultos e os demais, a criança vai desenvolvendo suas funções psíquicas dentro da escola, e a longo prazo, a criança se apropria das aprendizagens, tornando-as parte de si. Davidov assimila o aprendizado como inerente com base no desenvolvimento histórico e social. Ainda, de acordo com Libâneo e Freitas (2013, p. 325), Davidov defendia que "o aprendizado não é, em si mesmo, desenvolvimento, mas, se organizado corretamente, ativa processos de desenvolvimento mental da criança que seriam impossíveis fora do processo de aprendizado".

Assim como Davidov, outros autores como Daniil Borisovich Elkonin, Piotr Yakovlevich Galperin, Alexis Nikolaevich Leontiev e Leonid Vladimirovich Zankov, foram discípulos de Vygostsky em suas pesquisas sobre a teoria histórico-cultural.

Davidov e Elkonin concluíram em suas pesquisas que para as crianças, em idade escolar, devem ser oportunizadas "transformações básicas por meio da atividade de estudo, do pensamento teórico-abstrato e da livre regulação da conduta" (Libâneo; Freitas, 2013, p. 325). Assim, seria importante que o ensino fosse organizado de acordo com as zonas de desenvolvimento proximal (ZDP), um conceito central na Psicologia histórico-cultural de Vygotsky.

Posteriormente, diferenciou o pensamento teórico do pensamento empírico e de que forma precisariam ocorrer nas escolas. Assim,

O pensamento teórico é um nível ou qualidade de pensamento caracterizado pela habilidade (e motivação) de revelar a essência, as características substanciais e as relações de um objeto. É distinto do pensamento empírico, que é mais direcionado para características superficiais e relações de fenômenos (LOMPSCHER; GIEST, 2003, p. 270, grifo meu).[2]

RC: 88296

Disponível em: https://www.nucleodoconhecimento.com.br/educacao/ensino-desenvolvimental 
A alma desse ensino desenvolvimental, para Davidov, é a teoria da atividade de estudo, sendo uma prática a ser desenvolvida por toda criança desde as séries iniciais. O que ele sempre buscou foi a caracterização do nível psíquico de desenvolvimento de seus objetos durante a realização das atividades de estudo.

A teoria do ensino desenvolvimental ficou conhecida como sistema Elkonin-Davidov. Houve formação para que os professores russos trabalhassem com esse sistema. Muito se enfatiza nesse sistema o diálogo com outras culturas, visando a essencialidade de cada uma sem sobreposição de uma à outra. Assim, aos poucos foram criando-se métodos para elaboração das disciplinas e programas escolares, de modo que, por meio de experimentos, fossem investigados, com mediação, os processos das formações mentais dos alunos durante a realização de suas atividades.

\subsection{A TEORIA DO ENSINO DESENVOLVIMENTAL E O CONCEITO DE ATIVIDADE}

A essencialidade desta teoria é o conceito de atividade, sendo este conceito a ponte entre o viver e a existencialidade extrínseca. Toda atividade é entendida como um processo de transformação da realidade por meio a ação de outro indivíduo. Desta maneira acontecem as apropriações advindas das práticas sociais e culturais. Assim, as atividades denominadas coletivas são reproduzidas. Essas atividades são adquiridas no contexto histórico-cultural que se tornam intrínsecas, ou seja, individuais.

Davidov ainda internaliza os elementos da teoria de Leontiev, ao descrever que a atividade está relacionada com a criação ou modificação de algo físico ou espiritual, mas vai além da concepção de Leontiev ao adicionar, o desejo. "O desejo é essencial na estrutura interdisciplinar da atividade (...) é o núcleo básico de uma necessidade" (Davidov, 1999, p. 41). Ainda considerou que as ações se baseiam mais em desejos que motivos e que as ações dos seres humanos consideram mais as emoções. Ainda salienta que

RC: 88296

Disponível em: https://www.nucleodoconhecimento.com.br/educacao/ensino-desenvolvimental 
O mais importante na atividade científica não é a reflexão, nem o pensamento, nem a tarefa, mas a esfera das necessidades e emoções (...). Emoções são muito mais fundamentais do que pensamentos, elas são a base para todas as diferentes tarefas que um homem estabelece para si mesmo, incluindo as tarefas de pensar. (...) O mais importante é que as emoções capacitam uma pessoa a decidir, desde o início, se, de fato, há meios físico, espirituais e morais necessários para que ela alcance seu objetivo (DAVIDOV, 1999, p. 45, grifo meu)[3]

Assim, o pensamento teórico estende-se a conceitos, que quando transformados em ferramentas, podem ser aplicados nos problemas do cotidiano. O que Davidov propõe é um ensino que promova as potencialidades do aluno.

Formar conceitos é a relação do entendimento dos processos conhecimento, ensino/aprendizagem e atividade de estudo. A finalidade é a construção do pensamento teórico científico no aluno. Dessa forma cabe ao professor realizar as devidas investigações com finalidades fundamentais para o processo de ensino/aprendizagem, estruturando e planeando as atividades que serão realizadas pelos alunos.

Consequentemente, a tomada de consciência "implica, pois, numa relação de alteridade da pessoa para consigo mesma, adquirida através da autoestimulação produzida pela palavra. O conhecimento e o reconhecimento são funções da palavra, sendo que uma outra pessoa está sempre presente na sua formulação" (Toassa, 2006, p. 64). Compreende-se que os conceitos científicos, que são mediados por demais conceitos, instituem a tomada da consciência.

Ocorre que o indivíduo replica os conceitos já existentes ao apropriar-se deles. $\mathrm{Na}$ prática esses conceitos já existentes são referência para suas ações. Libâneo e Freitas sintetizam que

(...) No processo de aprender um objeto científico, o seu conceito, isto é, sua forma idealizada (pensada) vem sempre primeiro, antecedendo sua forma particular. Por exemplo, aprender o conceito de número enquanto conceito mais geral expressivo das relações de quantidade é a condição para que o aluno possa lidar com todos os tipos

RC: 88296

Disponível em: https://www.nucleodoconhecimento.com.br/educacao/ensino-desenvolvimental 
particulares de número e suas particulares expressões de relações de quantidade (LIBÂNEO; FREITAS, 2013, p. 335).

É importante, ao elaborar uma atividade, o professor mediar o conceito teórico para depois o aluno usá-lo de diferentes formas e contextos. Através da abstração o aluno chega aos conceitos dos objetos (conteúdos). A partir daí formulará sua manifestação concreta, pois já terá internalizado os conceitos. Davidov salienta que se a abstração acorrer de forma generalizada, o aluno conseguirá lidar com os objetos de conhecimento aplicando-os na resolução de problemas nas particularidades do seu cotidiano. Nessa passagem de conceito para o concreto existe ainda o pensamento empírico. De acordo com Libâneo e Freitas (2013, p. 336), "a formação do conceito empírico ocorre pela passagem do concreto sensorial ao abstrato, imaginável, levando a uma generalização empírica", o que permitirá que os alunos realizem operações mentais significativas.

A proposta de Davidov está na prerrogativa do pensamento teórico do aluno. Para ele, no pensamento teórico, o concreto se apresenta tanto no início como no resultado. Ainda é preciso que no processo de aprendizagem o aluno identifique a essência do objeto, fazendo assim suas próprias inferências. Nesse sentido, "para a psicologia histórico-cultural, o problema central foi e continua sendo a mediação da mente e da consciência" (Zinchenko, 1998, p. 44).

\subsection{A TEORIA DO ENSINO DESENVOLVIMENTAL E ATIVIDADE DE ESTUDO}

A atividade de estudo contempla, no ensino desenvolvimental, o encargo do aluno em absorver a consciência social aperfeiçoada, consciência essa baseada nos estudos teóricos científicos. A atividade de estudo aponta para o entendimento. A importância está em formar um pensamento teórico correlacionado com a vivência do aluno, para que esse possa aplicá-lo de diferentes modos em casos particulares.

$\mathrm{RC}: 88296$

Disponível em: https://www.nucleodoconhecimento.com.br/educacao/ensino-desenvolvimental 
Deste modo, entende-se que a atividade de estudo é uma ação típica do homem enquanto ser social, que internaliza os processos que o leva a converter conteúdo para o conhecimento, que seria um novo produto mental.

De acordo com Davidov,

A atividade de estudo e o objetivo de estudo a ela correspondente estão ligados, antes de tudo, com a transformação do material quando, para além de suas particularidades exteriores, se pode descobrir, fixar e estudar o princípio interno ou essencial do material a ser assimilado e, desse modo, compreender todas as manifestações externas desse material. (DAVIDOV, 1999, p. 4, apud LIBÂNEO; FREITAS, 2013, p. 341).

O que acontece é a ligação do objeto de estudo com o conhecimento teórico, ocasionando a apreensão, tornando os conhecimentos teórico intrínsecos. Dado defende que a escola é o ambiente para que os alunos se preparem para a atividade de estudo, e ainda ressalta que a tarefa de aprendizagem deve levar ao seu desenvolvimento.

Uma tarefa deve ter intencionalidades, objetivos a serem alcançados pelos alunos. $\mathrm{O}$ professor ao planejar uma aula, uma tarefa, deve ter em mente propósitos de desenvolvimento que atinja seus alunos. Nenhuma tarefa deve estar desconexa do contexto de vivência de um aluno ou mesmo desvinculada de um objetivo a ser alcançado.

Falar em desenvolvimento do aluno e de sua personalidade é se ater em como a atividade de estudo, e os meios para que sejam realizadas, pode causar mudanças qualitativas na contribuição de uma melhor experiência de vida para os alunos, afinal a real aprendizagem acontece quando um aluno consegue se reorganizar mentalmente.

Nesse sentido, Mello ressalta que

é preciso que o educador descubra as formas mais adequadas de trabalho com o seu grupo. Isso se faz possível quando o educador

RC: 88296

Disponível em: https://www.nucleodoconhecimento.com.br/educacao/ensino-desenvolvimental 
conhece os níveis de desenvolvimento real e próximo das crianças, quando conhece as regularidades do desenvolvimento delas, ou seja, conhece quais as funções psíquicas que se encontram em desenvolvimento e determinada etapa e que constituem os períodos mais adequados às influências da educação, e, ainda, quando percebe qual atividade é principal para a criança em determinada etapa de seu desenvolvimento e propicia a experiência da criança sob tal forma de atividade (MELLO, 2004, p.152).

Todo o processo de compreensão, apreensão e assimilação de conteúdos/objetos que ocorrem na escola é aprendizagem. Ressalta-se ainda que a escola não é o único lugar para assimilação de saber, pois estes podem ser advindos do convívio social.

Assim, pode-se dizer que efetivar o ensino desenvolvimental é organizar o ensino de modo que o aluno habilite em si um grau de aprimoramento em que sua melhor aptidão o leve ao alcance da intelectualidade.

\section{ELKONIN-DAVIDOV: UM SISTEMA PARA TRANSFORMAÇÃO SOCIAL}

Como abordado anteriormente, o sistema Elkonin-Davidov enfatiza o desenvolvimento do pensamento. A teoria do ensino desenvolvimental foi resultado de uma pesquisa empírica experimental realizada por um tempo estimado de quarenta anos e foi considerada uma revolução pedagógica.

Foi através dessa pesquisa que novos currículos foram elaborados par as escolas de ensino primário, bem como os livros didáticos e instrumentos pedagógicos para os professores. O ensino desenvolvimental foi caracterizado por Davidov como uma referência para transformação do ser social e também pessoal do aluno. Toda transformação pessoal, emocional e intelectual na perspectiva de Davidov era desenvolvimento.

Davidov frisou que para o desenvolvimento da aprendizagem, é preciso que o aluno assimile seu conhecimento teórico por meio de operações mentais, seja de análise, de reflexão ou de planejamento. É através dessas condições mentais que o ensino

RC: 88296

Disponível em: https://www.nucleodoconhecimento.com.br/educacao/ensino-desenvolvimental 
desenvolvimental se diferencia do ensino da escola tradicional, pois esse sistema propicia a transformação do aluno com foco na sua autonomia e autenticidade, ou seja, nesse sistema o aluno é legitimista da sua aprendizagem.

\subsection{CARACTERÍSTICAS DO ENSINO DESENVOLVIMENTAL}

A teoria de Vygotsky materializou-se com Davidov com algumas poucas diferenças, destacando sempre a importância da teoria e de seus conceitos. Como já citado, também integrou em sua teoria os elementos de Leontiev no que diz respeito à atividade do ser humano.

Tendo em vista esses fundamentos, Freitas e Libâneo (2019) classificam as características do ensino desenvolvimental de acordo com Davidov da seguinte forma:

- Finalidade a ampla transformação pessoal e social do aluno;

- Desenvolvimento como transformações essenciais nas esferas intelectual, emocional e pessoal dos alunos;

- Apropriação da cultura material e intelectual como a forma universal de promover o desenvolvimento dos alunos;

- Desenvolvimento do aluno associado ao domínio dos métodos de pensamento e de ação subjacentes aos conceitos;

- Apropriação de conceitos e subjacentes métodos generalizados de pensamento e de ação como conteúdo principal do ensino e aprendizagem;

- Tarefa de estudo que assegura a realização de ações mentais reprodutivas e criativas pelos alunos. (FREITAS; LIBÂNEO, 2019, p. 376).

Destaca-se aqui a importância do trabalho em conjunto, onde professor aluno se unem para apropriar e compartilhar conhecimentos. O papel da escola é justamente a de formar alunos que tenham autonomia e independência. É da escola a função de

RC: 88296

Disponível em: https://www.nucleodoconhecimento.com.br/educacao/ensino-desenvolvimental 
articulação para que seu currículo se aproxime dos interesses e das práticas socioculturais dos alunos.

Apropriar-se dos conhecimentos na didática desenvolvimental, depende da concreta participação do aluno. Sendo ativos, eles conseguirão enfrentar qualquer situação de seu cotidiano. Isso não significa que o aluno deve aprender sozinho, pelo contrário, é preciso que toda ação no processo de ensino/aprendizagem seja mediada e que tenha intencionalidades que desenvolva o aluno qualitativamente.

\section{CONTRIBUIÇÕES PARA METODOLOGIA DE CONSTRUÇÃO DE SISTEMAS}

O trabalho empreendido por D. B. Elkonin e V. V. Davidov, bem como a história da construção do mesmo, serviu, não apenas como referência para a implementações no campo educacional, mas também como parâmetro metodológico para que outros pesquisadores pudessem teorizar, experimentar, validar futuras investigações e/ou novos sistemas, tendo em vista sua execução prática, auxiliando na previsão dos possíveis desafios a serem enfrentados por futuros grupos de estudo, frente a qualquer nova descoberta que fosse realizada (PUENTES, 2017). Ao longo de várias décadas de história, a magnitude do trabalho de Elkonin e Davidov tornou-se alvo de intensas avaliações, de modo que foi possível identificar, ao menos, cinco fases, bem definidas e que marcaram toda a trajetória de suas atividades, que serão abordadas em tópicos separados.

\subsection{FASE I (1958-1975) - IDEALIZAÇÃO, EXPERIMENTAÇÃO E CONCEPÇÃO DO SISTEMA}

Ao final de 1958, Elkonin deu início a estudos psicológicos da atividade, em crianças em idade escolar, sendo o marco das primeiras ações no sentido de idealizar, elaborar e estabelecer os princípios fundamentais do que se tornou uma nova teoria e um novo sistema psicopedagógico: a teoria da atividade de estudo e o sistema Elkonin-Davidov

RC: 88296

Disponível em: https://www.nucleodoconhecimento.com.br/educacao/ensino-desenvolvimental 
(LAZARETTI, 2011). A partir de então, realizaram-se pesquisas de laboratório, empreendidas, a princípio, por uma reduzida equipe de experimentadores, reunidos de desligamentos da Divisão de Psicologia da Universidade Estatal de Moscou, entre estes Davidov. Esse grupo desempenhou um papel muito importante para o desenvolvimento do sistema Elkonin-Davidov.

Além das pesquisas de laboratório (internas), foram realizados experimentos formativos em ambientes escolares (externos), nos anos iniciais da educação geral básica (escola primária) e algumas disciplinas entre os alunos do ensino médio. Durante dois primeiros anos de estudo, foram publicados os resultados iniciais. Os objetivos eram: determinar o conteúdo e a estrutura das atividades de estudo dos alunos; estruturar as bases lógico-psicológicas das disciplinas escolares; entender as peculiaridades do desenvolvimento psíquico dos alunos; pesquisar ressalvas ao desenvolvimento psíquico, nos diferentes anos escolares e das características particulares na organização do experimento formativo (DAVIDOV, 1988).

Tal atividade ganhou destaque a partir de 1960, quando Davidov assumiu o cargo de diretor do Laboratório, substituindo Elkonin e, principalmente, no ano de 1963, quando a Academia de Ciências Pedagógicas concedeu o status de instituição de ensino experimental à Escola Experimental no 91 de Moscou (primeira instituição em que foram aplicados os experimentos educacionais). Rapidamente, a proposta se estendeu para várias regiões da União Soviética, com o surgimento de novos grupos e laboratórios. As características mais marcantes dessa primeira foram: 1) A elaboração das bases de uma teoria psicológica do ensino; 2) A elaboração de uma teoria da generalização substantiva (ou teórica); 3) O desenho de uma teoria didática do ensino; 4) O desenvolvimento de uma teoria do diagnóstico da atividade de estudo e; 5) A elaboração de um programa de formação dos professores das escolas experimentais (PUENTES, 2017).

RC: 88296

Disponível em: https://www.nucleodoconhecimento.com.br/educacao/ensino-desenvolvimental 


\subsection{FASE II (1975-1983) - CONSTRUÇÃO DE CONDIÇÕES O SISTEMA SE UNIVERSALIZASSE}

Os frutos teóricos e objetivos do sistema Elkonin-Davidov chamaram a atenção graças ao desempenho superior dos alunos das salas experimentais, quando comparados com os alunos do ensino tradicional, em 3 pontos: nível de desenvolvimento do pensamento teórico, resolução de problemas e autoaprendizagem. O sistema acabou por adquirir reconhecimento científico e didático-metodológico, após a boa expressão em livros e materiais de apoio e, junto com o sistema Zankoviano, a ser avaliado como uma possibilidade pedagógica relativamente diferente: a atenção de especialistas em educação e do próprio Ministério da Educação se voltaram para tal projeto, permitindo que, em 1970, o Ministro da Educação da União Soviética, Mikhail A. Prokof'ev, oferecesse a Davidov, a elaboração de um sistema de educação básica que incorporasse a concepção teórica criada por ele, Elkonin e os diferentes grupos. Então, o que inicialmente se limitava a um projeto teórico, aplicado a um número ainda pequeno de escolas experimentais, agora precisava ser concebido e implementado em grande escala (PUENTES, 2017).

As demandas passaram a ter um caráter objeto-substantivo, curricular, didático, metodológico, de organização pedagógica, bem como de formação de professores. Foi necessário desenvolver o conteúdo e a lógica de construção de programas de ensino primário, em língua russa e matemática; redigir os materiais instrucionais para os professores e elaborar o método de ensino, ao mesmo tempo em que os pesquisadores e membros do sistema Elkonin-Davidov davam continuidade a suas atividades de pesquisa experimental e de divulgação científica, nas diferentes cidades em que operavam (PUENTES; AMORIM; CARDOSO, 2016).

No entanto, o trabalho acabou encerrado temporariamente por um conjunto de fatores: em 1983, uma época de grande censura e perseguição política, Davidov acabou expulso do Partido Comunista e, consequentemente do Instituto de Psicologia; Mikhail A. Prokof'ev saiu de seu cargo no governo e, em 1984, houve a morte de D. B. Elkonin.

RC: 88296

Disponível em: https://www.nucleodoconhecimento.com.br/educacao/ensino-desenvolvimental 
Devido a esse conjunto de acontecimentos negativos, o processo de implementação do sistema foi interrompido na educação de massa. No entanto este já havia se tornado um sistema sólido e acabado. (REPKIN; REPKINA, 1997, p. 12).

\subsection{FASE III (1983-1986) - CENSURA, PERSECUÇÃO, DISSOLUÇÃO E PARALISAÇÃO DO PROCESSO DE IMPLEMENTAÇÃO DO SISTEMA}

Com a destituição de Davidov e morte de Elkonin, embora o trabalho experimental tivesse sido oficialmente interrompido e o grupo de pesquisa dissolvido, a maior parte dos membros continuou envolvida em atividades de pesquisa e experimentação teórica por sua própria responsabilidade, adaptando-se às novas condições e oportunidades que surgiam. Além disso, o cabedal de conhecimento gerado até então, já havia ganhado o grande público: pesquisadores, estudiosos e interessados tinham acesso ao que fora publicado e a própria escola primária no 91 continuou a atuar com o sistema implantado o que deu origem a novas publicações. Embora o trabalho de Davidov-Elkonin houvesse sido oficialmente extinto, nada impediu que professores e estudantes desenvolvessem teses acadêmicas e/ou fizessem publicações sobre o tema, o que manteve tal debate aquecido na comunidade educacional (PUENTES, 2017).

\subsection{FASE IV (1986-1994) - IMPLEMENTAÇÃO DO SISTEMA COMO ALTERNATIVA OFICIAL DO MINISTÉRIO DA EDUCAÇÃO}

No ano de 1986, o Partido Comunista da União Soviética (PCUS), reconhecendo a expulsão de Davidov como um grave equívoco, o reintegrou ao partido e à direção do Instituto de Psicologia e às pesquisas experimentais. Na verdade, tal decisão marcava o fim de uma triste etapa na história da educação no país, que havia sofrido com a censura, perseguições variadas e críticas e, ainda, o fim da ilegalidade, tanto de Davidov como de todos os outros membros do sistema Elkonin-Davidov. Abriu-se uma fase caracterizada pelo trabalho de implementação do sistema, como alternativa

RC: 88296

Disponível em: https://www.nucleodoconhecimento.com.br/educacao/ensino-desenvolvimental 
oficial do Ministério da Educação na educação básica, especialmente, no ensino de nível primário, que vinha como solução principal para a solução dos enormes problemas de qualidade, que ainda assombravam o tradicional sistema de educação nacional (LIBÂNEO; FREITAS, 2013).

É nessa época que Davidov publica sua mais proeminente obra, Problemas do ensino desenvolvimental: pesquisa psicológica teórica e experimental, que trata de várias questões da psicologia geral, infantil (evolutiva) e pedagógica, numa argumentação sustentada por mais de duas décadas de pesquisa teórica e dados sólidos, coletados a partir de resultados práticos obtidos nas escolas experimentais. Com a publicação desta obra, o sistema didático desenvolvido pelo Elkonin e Davidov, em parceria com numerosos pesquisadores e professores experimentais, passou a ser conhecido, tanto na União Soviética como no exterior. Aos poucos os grupos voltaram ao trabalho, voltados para o objetivo de esclarecer as possibilidades e condições para a introdução do sistema de Ensino Desenvolvimental na escola de educação de massas, no entanto, embora houvesse total liberdade para tal, não houve investimento do governo em tais empreendimentos (REPKIN; REPKINA, 1997, p. 16).

A situação mudou em 1990, quando o Ministério da Educação formou o Instituto de Inovação Pedagógica da Academia de Ciências Pedagógicas da União Soviética e os vários grupos que integravam o sistema Elkonin-Davidov foram vinculados ou associados ao Instituto por ideia do próprio Davidov, na forma de laboratórios independentes. Foram desenvolvidos materiais didáticos, de avaliação, livros, manuais pedagógicos e centros de formação de professores. Mas apesar dos esforços e do panorama político otimista, o sistema Elkonin-Davidov encarou o sério problema da fragmentação do socialismo na Europa, em 1989 e a posterior fragmentação da União Soviética, em 1991, que levou os grupos cujas bases estavam fora da Rússia a se desassociarem do Instituto de Inovação Pedagógica. Houve uma perda drástica da ajuda institucional e financeiro dos grupos, já que estes tiveram que buscar apoio nas novas nações constituídas e das quais agora faziam parte, o que causou a extinção de vários grupos e centros de pesquisas. E, embora o trabalho de

RC: 88296

Disponível em: https://www.nucleodoconhecimento.com.br/educacao/ensino-desenvolvimental 
Davidov não houvesse sido barrado, houve grave redução de seu lastro de atuação, precisando se encaixar em uma nova realidade sócio-política, para que fosse possível dar continuidade à produção do material didático, formar professores e implantar o sistema nas escolas.

\subsection{FASE V (1994-ATUALIDADE) - INTERNACIONALIZAÇÃO E CONSOLIDAÇÃO DO SISTEMA}

Através das mudanças, o sistema Elkonin-Davidov foi capaz de ser moldável o suficiente para se adaptar à nova realidade do leste europeu, crescendo e se consolidando, adentrando o século XXI com novo fôlego. Houve a internacionalização da teoria, com a criação da Associação Internacional de Ensino Desenvolvimental do Sistema Elkonin-Davidov e a consolidação do sistema, ao se constituir em um dos três sistemas oficiais de ensino primário em vários dos novos países que se criaram, a partir das antigas repúblicas soviéticas, mesmo após a morte de Davidov.

No começo dos anos 2000, o sistema Elkonin-Davidov era utilizado por 2.500 escolas, com grupos integrados de trabalho com mais de 1.800 participantes, entre pesquisadores, professores, colaboradores e diretores de escolas, atuando ao longo de 72 regiões da Rússia, Ucrânia, Letônia, Cazaquistão e Belarus. Além disso, maior abertura da Rússia e das antigas repúblicas soviéticas, permitiu que o trabalho de Elkonin e Davidov ganhasse o mundo (PUENTES, 2017).

No entanto, reconhece-se que, embora o sistema Elkonin-Davidov seja uma proposta consolidada, esta surgiu com base nas diferentes tendências que se constituíram ao longo de mais de cinquenta anos de construção de um sistema de ensino e de educação no contexto da edificação, principalmente, da sociedade socialista soviética. E o fato de ter sido abandonada e depois resgatada, abriu precedentes para que, nesse ínterim, a mesma fosse estudada e aplicada, de forma seccionada, por vários pesquisadores e grupos de pesquisa independentes e desvinculados de Davidov.

RC: 88296

Disponível em: https://www.nucleodoconhecimento.com.br/educacao/ensino-desenvolvimental 
No Brasil, por exemplo, a compreensão do que seja o ensino desenvolvimental não é muito exata, bem como o não-entendimento de que esta seja uma expressão educativa no singular, própria, como um paradigma teórico coeso, homogêneo e coerente. Dessa forma, expressões como a didática desenvolvimental, o sistema Elkonin-Davidov, a teoria da atividade de estudo, o sistema Zankoviano e a teoria da formação por etapas das ações mentais e dos conceitos de Pa. Ya. Galperin e de N. F. Talízina, dentre outros, comumente são identificados indistintamente, ou seja, como se fossem participassem do mesmo universo temático (PUENTES, 2017). Na verdade, estes têm pontos de vista comuns, apesar de grandes discrepâncias teóricometodológicas internas, além de acentuadas divergências conceituais em relação à interpretação das teses fundamentais de Vigotski, sobre o lugar e o papel do ensino e da educação no desenvolvimento humano (DAVIDOV, 1996). Pode-se dizer que o sistema Elkonin-Davidov, no ocidente, mais contribui com a formação de outros sistemas do que é efetivamente aplicado em sua integridade.

\section{CONSIDERAÇÕES FINAIS}

Este artigo trouxe algumas das contribuições de Vygotsky e de seus seguidores, especificamente Davidov e Elkonin. Sua finalidade foi de apresentar, mesmo que de forma sintetizada, como sugere o título, a teoria histórico-cultural e a proposta do ensino desenvolvimental.

O que fica evidente é que a escola deve pensar em estratégias de aprendizagem que possibilite o pleno desenvolvimento do aluno, sendo este um ser social que precisa de formação não apenas conteudista, como também crítica. É preciso que a escola vise a transformação de seus alunos com uma didática que contribua para a aprendizagem, que oportunize o desenvolvimento humano.

O presente texto, em particular, sobre o sistema Elkonin-Davidov, não o esgota, pelo contrário: cria condições para um estudo futuro ao localizar e analisar as etapas mais importantes na construção de tal sistema, com os diversos constituintes que o

RC: 88296

Disponível em: https://www.nucleodoconhecimento.com.br/educacao/ensino-desenvolvimental 
compõe, as diferentes teorias desenvolvidas ao longo de décadas de pesquisa e experimentação, com suas frentes de trabalho mais relevantes e as numerosas e valiosas obras geradas como fruto desse trabalho.

Concluo este artigo enfatizando aos professores a seriedade de promoverem em seus alunos o desenvolvimento do pensamento crítico, destacando que a dialética nesse processo de ensino/aprendizagem é primordial para troca de experiências. Conhecer o público com o qual se trabalha auxilia todo o processo de ensinagem. Através da mediação de conhecimentos não só o aluno, mas também o professor adquirirá conhecimentos histórico-culturais que aperfeiçoarão sua inteligência e sua personalidade nesse tempo.

\section{REFERÊNCIAS}

DAVIDOV, V. V. Problemas lógicos-psicológicos das matemáticas elementares como matéria de estudo. In: ELKONIN, D. B.; DAVIDOV, V. V. (Orgs.). Возрастные возможности усв оени я з н аний (м лад ш ие классы школы). Moscou: Prosveshchenie, 1966.

DAVYDOV, V. V. A new approach to the interpretation od activity structure and contente. In: HEDEGAARD, M.; JENSEN, U. J. Activity theory and social practice: cultural-historical approaches. Aarhus (Dinamarca): Aarhus University Press, 1999, p. $39-50$.

Problemas do ensino desenvolvimental: A Experiência da Pesquisa Teórica e Experimental na Psicologia. Revista Soviet Education, v. 30, n. 8, 1988. Disponível em: <http://webcache.googleusercontent.com/search?q=cache:zKkjFVU0tUJ:professor.pucgoias.edu.br/SiteDocente/admin/arquivosUpload/5146/materi al/DAVYDOV\%2520TRADU\%25C3\%2587\%25C3\%25830\%2520PROBLEMS\%252 0OF\%2520DEVELOPMENTAL\%2520TEACHING\%2520(Livro).doc+\&cd=1\&hl=ptBR\&ct=clnk\&gl=br>. Acesso em 27 mar. 2021.

$\mathrm{RC}: 88296$

Disponível em: https://www.nucleodoconhecimento.com.br/educacao/ensino-desenvolvimental 
FREITAS, R. A. M. da M., \& LIBÂNEO, J. C. (2019). Didática desenvolvimental e políticas educacionais para a escola no Brasil. Linhas Críticas, 24. https://doi.org/10.26512/lc.v24i0.21850. Acesso em: 02 de novembro de 2020.

LAZARETTI, Lucinéia Maria. D.B. Elkonin: vida e obra de um autor da psicologia histórico-cultural. São Paulo: Editora Unesp, 2011.

LIBÂNEO, J. C.; FREITAS, Raquel A. M. M. Vasily Vasilyevich Davydov: A escola e a formação do pensamento teórico-científico. In: Ensino desenvolvimental: vida, pensamento e obra dos principais representantes russos/Andréa Maturano Longarezi Roberto Valdés Puentes. Organizadores. Uberlândia: EDUFU, 2013. p. 315 - 350.

LOMPSCHER, Joachim; GIEST, Hartmut. Formation of Learning Activity and Theoretical Thinking in Science Teaching. In: Vygotsky's Educational Theory in Cultural Context. Alex Kozulin. Cambridge University Press. 2003. p. 267 - 288.

LURIA, A. R. (1979). The making of mind. Cambridge, MA: Harvard University Press.

MELLO, Suely Amaral. A escola de Vygotsky. In: introdução à psicologia da educação: seis abordagens/Kester Carrara (organizador). - São Paulo: Avercamp, 2004. p. $135-155$.

PUENTES, R. V. Didática desenvolvimental da atividade: o sistema ElkoninDavidov (1958-2015). Obutchénie - R de Didat e Psic Pedag, v.1, n.1, 2017. Disponível em: <http://www.seer.ufu.br/index.php/Obutchenie/article/view/38113>. Acesso em 27 mar. 2021.

PUENTES, R. V.; AMORIM, P. A. P.; CARSOSO, C. G. C. V. V. Repkin: vida, pensamento e obra de um dos principais representantes da didática desenvolvimental da atividade. In: PUENTES, R. V.; LONGAREZI, A. M. (Orgs.). Ensino desenvolvimental: vida, pensamento e obra dos principais representantes russos. Livro III. Uberlândia: Edufu, 2016, p. 1-35. 
REPKIN, V.V.; REPKINA, N. V. Ensino desenvolvimental: teoria e da prática. Tomsk, 1997.

TOASSA, G. (2006). Conceito de consciência em Vigotski. Psicologia USP, 17(2), 59-83. Disponível em: https://doi.org/10.1590/S0103-65642006000200004. Acesso em: 02 de novembro de 2020.

ZINCHENKO, V. P. A psicologia histórico-social e a teoria psicológica da atividade: retrospectos e prospectos. In: WERTSCH, James V.; DEL RÍO, P.; ALVAREZ, Amélia. (Orgs.). Estudos socioculturais da mente. Porto Alegre: Artmed, 1998.

\section{APÊNDICE - REFERÊNCIA DE NOTA DE RODAPÉ}

2. Theoretical thinking is a level or quality of thinking characterized by the ability (and motivation!) to reveal the essence, the substantial features, and the relationships of an object (cf. Davydov, 1988). It is distinguished from empirical thinking, which is more directed toward superficial features and relationships of phenomena.

3. The most important thing in scientific activity is not reflection, nor thinking, nor the task, but the sphere of needs and emotions (...). Emotions are much more fundamental than thoughts, they are the basis for all the different tasks that a man establishes for himself, including the tasks of thinking. (...) The most important thing is that emotions enable a person to decide, right from the start, whether, in fact, there are the physical, spiritual and moral means necessary for him to achieve his goal.

Enviado: Abril, 2021.

Aprovado: Junho, 2021.

RC: 88296

Disponível em: https://www.nucleodoconhecimento.com.br/educacao/ensino-desenvolvimental 